\title{
Heat Losses from a Breathing System with a Heated-water Humidifier
}

\author{
J. N. LUNN, W. W. MAPLESON, E. K. HILLARD
}

British Medical fournal, 1971, 4, 653-656

\section{Summary}

Air was "breathed" in the laboratory through a heated-water humidifier and a breathing tube. Several different humidifiers and tubes were used. The temperature rise of the air on passing through the humidifier and the temperature drop on passing through the tube were measured. Both were dependent on ventilation. Insulating the tube and humidifier together with the insertion of baffles in the latter reduced the rise and fall and their dependence on ventilation. With suitable design the dependence on ventilation and the need to use high water temperatures could be greatly reduced. In addition, a thermostat with a reduced dead zone is needed.

\section{Introduction}

Two practices have been adopted to overcome the problem of heat loss from warmed, humidified gas as it passes along the breathing tube during upper airway bypass ventilation. In one, the thermostat of the humidifier is set at a "safe" level, with the result that the gas reaching the patient, though it may be fully saturated, is several degrees lower than body temperature (Macintosh, Mushin, and Epstein, 1963). In the other, the humidifier is set to maintain a high water temperature; the possibility then exists that hyperthermia (Kirch and De Kornfield, 1967) or scalding may occur, though the risk may be reduced by monitoring the temperature at the mouth (Sykes, 1969).

This investigation was undertaken to determine the amount of heat lost during passage along the tube, to find out whether it could be lessened, and, if so, what would be the consequences. It was also found that, apart from the thermal conductivity of the tube wall, the environmental temperature, and the rate of passage of the gas as factors influencing heat loss, an important source of uncertainty about the temperature of the gas reaching the patient is variation in the heat gain of the gas on passing through the humidifier.

\section{Methods and Materials}

The tubes investigated were (1) the standard, black, antistatic corrugated rubber tube; (2) the concentric plastic breathing tube supplied with the Harlow ventilator (Bushman and Robinson, 1968); (3) a polyethylene tube 1 metre long, $14 \mathrm{~mm}$ bore, 2-mm walls; (4) the same tube insulated for its full length with expanded-polystyrene rings, $35 \mathrm{~mm}$ overall diameter: and (5) a polyethylene tube 1 metre long, $16 \mathrm{~mm}$ bore, with 3-mm walls lagged with kapok to an overall diameter of about $70 \mathrm{~mm}$.

\footnotetext{
Department of Anaesthetics, Welsh National School of Medicine, Cardiff CF4 4XN

I. N. LUNN, M.D., F.F.A. R.C.S., Senior Lecturer

W. W. MAPLESON, PH.D., F.INST.P., Reader in the Physics of Anaesthesia

E. K. HILLARD, L.B.I.S.T., Chief Technician
}

A bag in bottle (Fig. 1) was used as an artificial lung. The bottle was surrounded by a heating element devised to maintain a temperature of $37^{\circ} \mathrm{C}$ within the bottle. Spontaneous

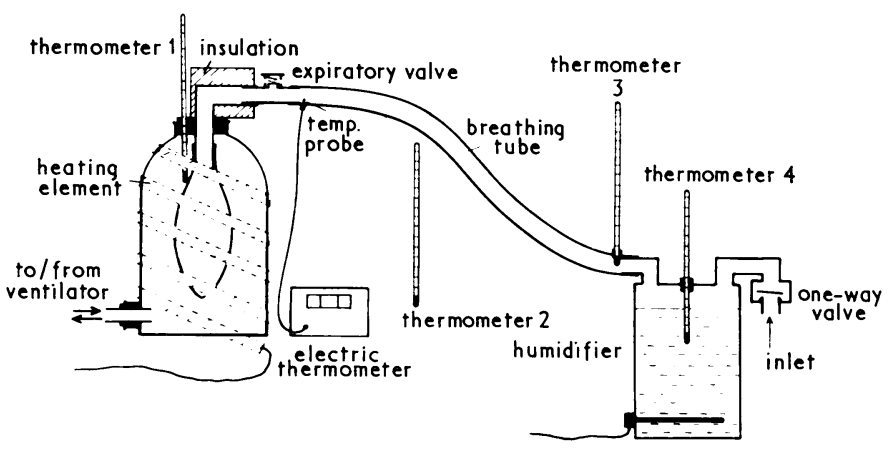

FIG. 1-The apparatus. Thermometer 1, "lung" temperature; electric thermometer, temperature at patient end of tube; thermometer 2 , room temperature; thermometer 3 , temperature at outlet of humidifier; thermometer 4 , temperature of water in humidifier.

ventilation was simulated by connecting a variety of automatic ventilators to the bottle. To provide a wide range of inspiratory to expiratory $(\mathrm{I}: \mathrm{E})$ time ratios three ventilators were used-a Cape Minor, a Beaver, and a modified Beaver.

The breathing tubes were connected into the circuit as they would be in normal use. The corrugated rubber tube, the polyethylene tube, the polyethylene tube insulated with polystyrene, and the lagged tube were each connected between the humidifier and a spring-loaded expiratory valve near the mouth. The Harlow tube had a spring-loaded expiratory valve connected in place of its pressure-operated expiratory valve; thus the expired gas passed down the whole length of the annular space around the inner (inspiratory) tube, as it does when the tube is used with the Harlow ventilator.

The humidifier used for most of our experiments was of the type described by Spalding (1956) from which most modern heated-water humidifiers have evolved. Some experiments were also performed with the East-Radcliffe (H4) humidifier. In addition, a Spalding-type humidifier was modified by the addition of baffles to improve contact between gas and water. Subsequently it was further modified by surrounding that part of the outside of the humidifier which encloses the air space above the water with a 25-mm layer of expanded polystyrene. In all experiments care was taken to ensure that the "full" mark, and therefore the space above it, was kept sensibly constant at the indicated level. A one-way valve fitted to the inlet port ensured that all expired gas passed to the atmosphere through the expiratory valve. The tidal volume was set with a Wright respirometer connected to the inlet port. The $I: E$ ratio and the frequency were measured from recordings made with a pneumotachograph similarly connected.

Three mercury-in-glass thermometers and one electric thermometer were positioned in the circuit (Fig. 1), and these, together with another mercury-in-glass thermometer registering room temperature, were read every 15 minutes. All experiments continued for several hours, in many cases seven hours, to ensure stable conditions. 


\section{Results}

The detailed results for one experiment using the corrugated rubber tube, a breathing frequency of $18 / \mathrm{min}$, a tidal volume of $750 \mathrm{ml}$, and an $\mathrm{I}: \mathrm{E}$ ratio of $1: 2 \cdot 8$ are shown in Fig. 2.

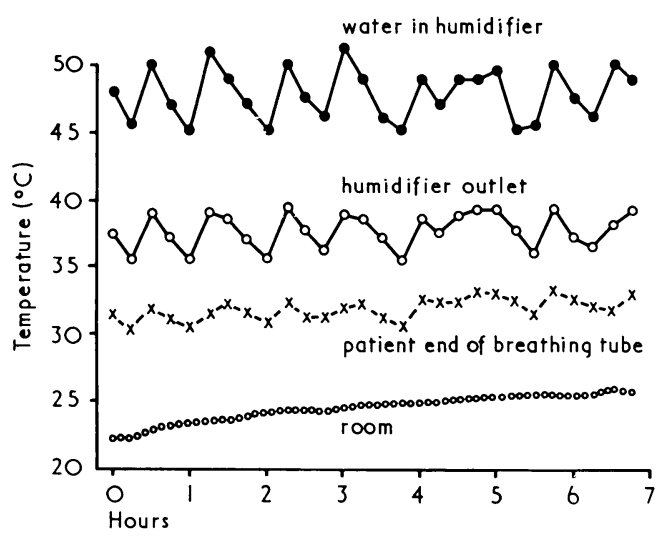

FIG. 2-Temperatures recorded during an experiment with antistatic corrugated rubber breathing tube and Spalding-type humidifier. Tidal volume $750 \mathrm{ml}$, frequency $18 / \mathrm{min}$, total ventilation $13.5 \mathrm{l} / \mathrm{min}$., I:E ratio volume
$1: 2 \cdot 8$.

The fluctuations in humidifier water temperature are due to the intermittent operation of the thermostat and they are transmitted throughout the breathing system.

\section{BREATHING TUBES}

For each of the 29 experiments the mean temperature for each thermometer was determined. From these figures the mean fall in temperature along the breathing tube was calculated as a percentage of the largest possible fall. This percentage was plotted against total ventilation for each tube (Fig. 3). Thus if the ventilation becomes very small the temperature of the gas will fall nearly to room temperature during the time it takes to travel through the tube-that is, the fall will be nearly $100 \%$ of the maximum possible. Conversely, if the ventilation becomes very large the temperature fall will be very small.

This manner of presentation was chosen because theoretically the percentage fall will be little affected by moderate changes in room and humidifier outlet temperature. In the

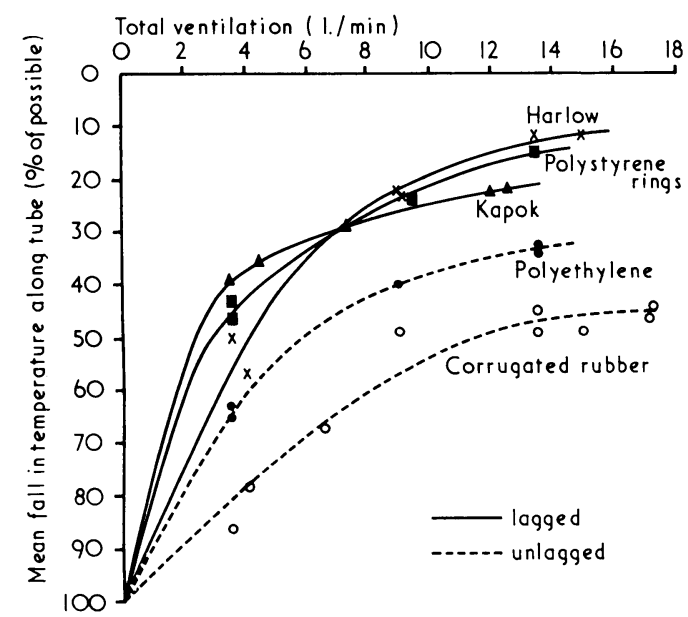

FIG. 3-Mean fall of temperature along the breathing tube as a percentage of the largest possible fall,

$$
\frac{T_{\text {ho }}-T_{\text {pe }}}{T_{\text {ho }}-T_{r}} \times 100,
$$

against total ventilation for experiments with five different bieathing tubes. against total ventilation for experiments with five different bieathing tubes. $T_{h o}=$ temperature at the outlet of the humidifier, $T_{p}$
the patient end of the tube, and $T_{r}=$ room temperature. experiments the range of mean room temperature was $20-26^{\circ} \mathrm{C}$ and the range of mean humidifier outlet temperature was $36-45^{\circ} \mathrm{C}$.

The lines in Fig. 3 show the differences between individual tubes and how the temperature fall decreases as the total ventilation increases. Most of the results were obtained with a respiratory frequency of $18-20 / \mathrm{min}$. However, on two occasions when a frequency of $12 / \mathrm{min}$ was used the results coincided with those for $18 / \mathrm{min}$ at the same total ventilation. On this account the results throughout are related to total ventilation and not to tidal volume. $A$ range of $I: E$ ratios

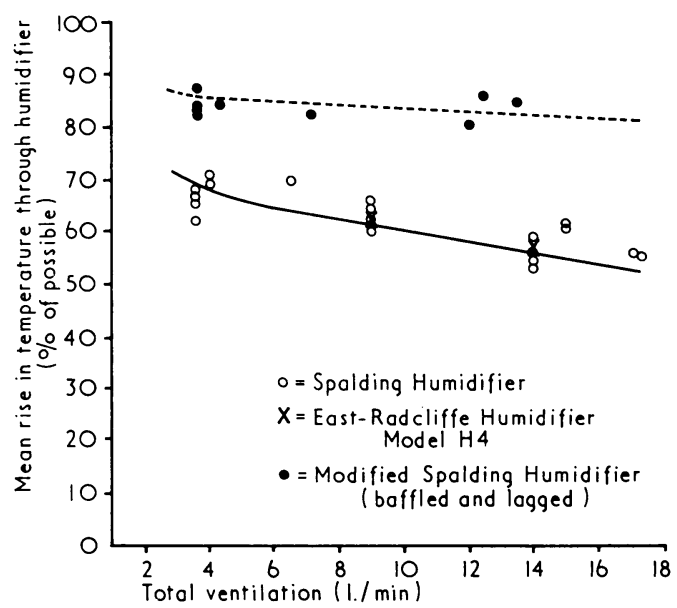

FIG. 4-Mean rise in temperature of gas passing through the humidifier as a percentage of the largest possible increase,

$$
\frac{\mathrm{T}_{\text {ho }}-\mathrm{T}_{\mathrm{r}}}{\mathrm{T}_{\mathrm{w}}-\mathrm{T}_{\mathrm{r}}} \times 100,
$$

related to total ventilation for experiments with three humidifiers. $T_{w}=$ temperature of water in the humidifier, $T_{h o}$ and $T_{r}$ as in Fig. 3.

$(1 \cdot 5: 1-1: 6)$ is incorporated in Fig. 3. Detailed examination of the individual results showed that this had no important effect.

Within experimental limits there is not much difference between the Harlow tube, the tube lagged with kapok, and the polyethylene tube lagged with expanded polystyrene (Fig. 3). Not surprisingly, all three show considerably less heat loss than the plain polyethylene and corrugated rubber tubes.

\section{HUMIDIFIERS}

For each of the 29 experiments the mean rise in temperature of the gas passing through the humidifier was calculated as a percentage of the largest possible rise. The largest possible rise would occur when the gas temperature rose to equal the temperature of the water in the humidifier. This percentage rise was plotted against total ventilation for various humidifiers (Fig. 4). It can be seen that the temperature rise becomes less as the ventilation increases, particularly in the unmodified humidifiers.

When baffles were fitted to the Spalding humidifier to improve contact between gas and water there was little increase in overall heat transfer because heat loss continued through the top cover of the humidifier. When this was lagged a considerable improvement in heat transfer was obtained.

\section{Deductions}

When the behaviour of the two elements of the system had been established the implications of different combinations were then explored theoretically. The humidifier water temperature required to ensure a mean temperature at the patient 
end of the breathing tube of $37^{\circ} \mathrm{C}$ at a total ventilation of $81 . / \mathrm{min}$ and a room temperature of $22^{\circ} \mathrm{C}$ was calculated from the curves in Figs. 3 and 4. Then, given this mean water temperature, the effect of changes from the mean due to the thermostat $\left( \pm 3^{\circ} \mathrm{C}\right)$ and the effect of changes in total ventilation were also calculated from the curves. The results of these calculations are shown in Figs. 5 to 7.

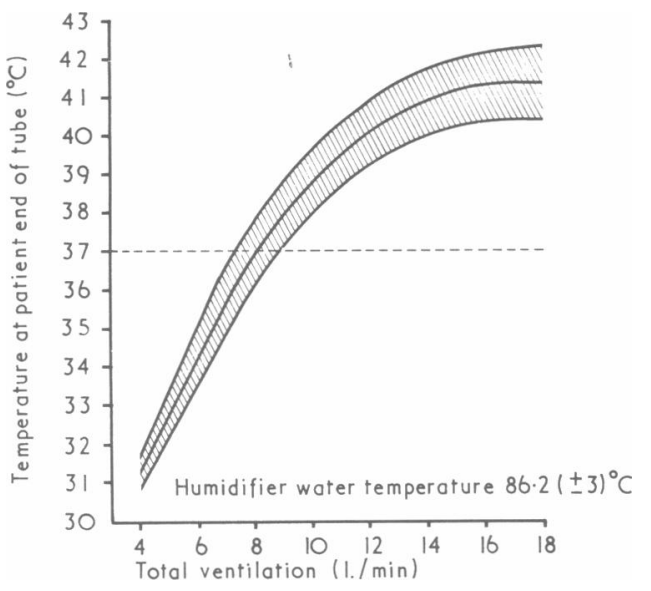
FIG. 5-Calculated relationship between temperature at the patient end of a corrugated rubber tube and total ventilation. Assumptions: room temperature $22^{\circ} \mathrm{C}$, humidifier water temperature that which is necessary to achieve
a temperature at the patient end of the tube of $37^{\circ} \mathrm{C}$ at a ventilation of a temperature at the patient end of
81 ./min. with a Spalding humidifier.

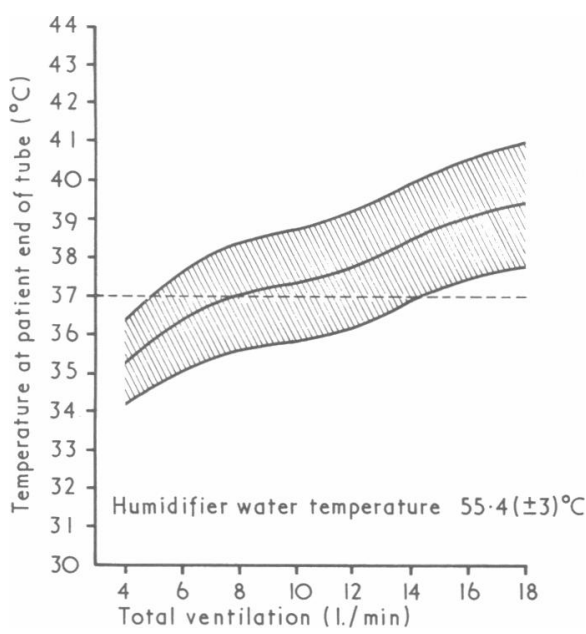

FIG. 6-Calculated relationship between temperature at the patient end of a polystyrene-insulated polyethylene tube and total ventilation. Assumptions as in Fig. 5.

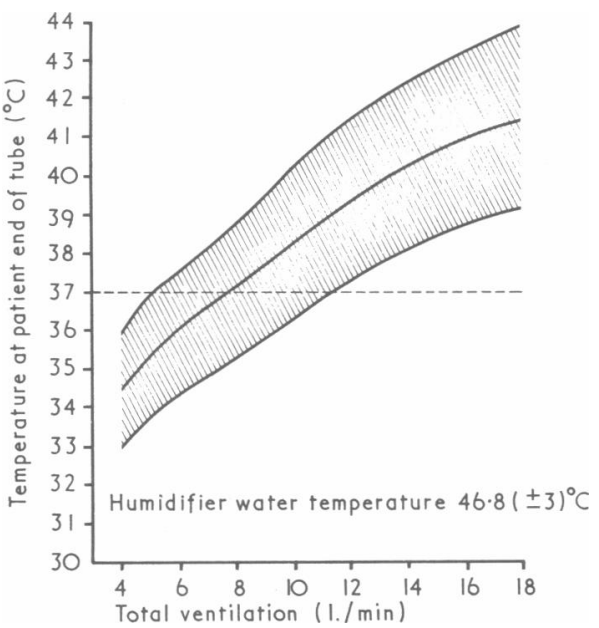

FIG. 7 -Calculated relationship between temperature at the patient end of a polystyrene-insulated polyethylene tube and total ventilation with a modified Spalding humidifier. Other assumptions as in Fig. 5.
Fig. 5 shows that with the ordinary corrugated rubber tube and unmodified humidifier an extremely high humidifier temperature $\left(86.2^{\circ} \mathrm{C}\right)$ is required, and the temperature at the patient end of the tube is very dependent on total ventilation. Fig. 6 shows that when the polystyrene-insulated tube is substituted a much lower humidifier temperature $\left(55.4^{\circ} \mathrm{C}\right)$ may be used and dependence on total ventilation is much reduced. Fig. 7 shows that when in addition the modified humidifier is substituted an even lower humidifier water temperature can be used, but dependence on total ventilation again becomes pronounced. At the same time the temperature fluctuations due to the thermostat are much more evident. It is apparent that improvements in tube and humidifier call for reduction of the dead zone of the thermostat.

In both spontaneous and controlled ventilation, and particularly on changing from one to the other, the magnitude of ventilation may change considerably. As Figs. 5, 6, and 7 show, the temperature at the patient end of the tube depends on ventilation. Ideally this dependence should be eliminated, and to achieve this the dependence on ventilation of the temperature fall through the tube (Fig. 3) should be exactly cancelled by the dependence on ventilation of the temperature rise through the humidifier (Fig. 4). By combining the lagged tube and the ordinary humidifier (Fig. 6) the ideal is approached. To achieve it completely, however, somewhat better lagging is needed, even when the unmodified humidifier is used. Finally, if advantage is to be taken of the reduced humidifier water temperature which is possible with the modified humidifier (Fig. 7) while still avoiding dependence on ventilation, a much more efficiently insulated breathing tube is desirable.

Figs. 5, 6, and 7 refer to the practice of using a high water temperature in the humidifier to achieve the desired temperature at the patient end of the breathing tube. On the other hand, Fig. 8 shows that if the temperature is set to a "safe"

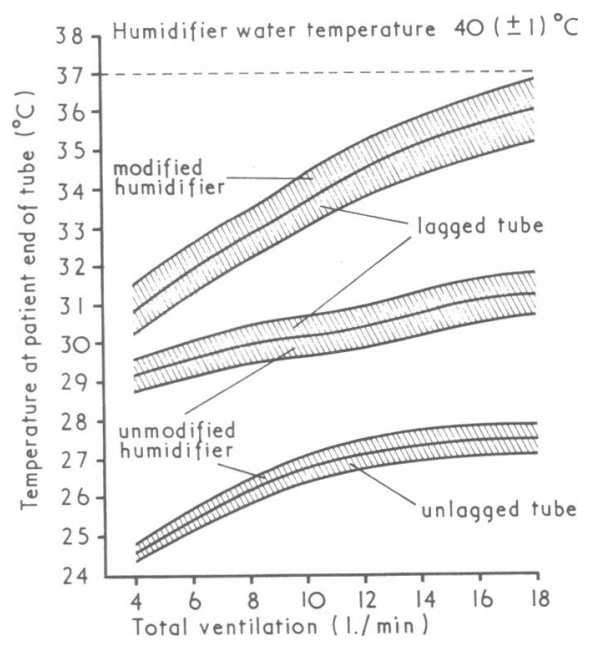

FIG. 8-Calculated relationship between temperature at the patient end of the three breathing tubes and total ventilation with a humidifier water temperature maintained at $40 \pm 1^{\circ} \mathrm{C}$. Room temperature $22^{\circ} \mathrm{C}$.

level $\left(40^{\circ} \mathrm{C}\right)$ and if an improved thermostat $\left( \pm 1^{\circ} \mathrm{C}\right)$ is fitted, the mean temperature at the patient end of the tube, at $81 . /$ min ventilation and a room temperature of $22^{\circ} \mathrm{C}$, is increased from about $26^{\circ} \mathrm{C}$ with the corrugated tube and unmodified humidifier to about $30^{\circ} \mathrm{C}$ with the polystyrene-insulated tube, and to about $33^{\circ} \mathrm{C}$ with the addition of the modified humidifier.

\section{Conclusion}

Conventional heated-water humidifiers and breathing tubes are ineffective or hazardous. Our studies confirm that lagging the breathing tube improves the performance considerably. 
Furthermore, they show that the system can be made both inherently safe and effective by using baffles inside and lagging on top of the humidifier, by thoroughly insulating the breathing tube, reducing the dead zone of the thermostat, and maintaining a water temperature only slightly above body temperature.

We thank Professor W. W. Mushin for his encouragement and constructive criticism.

\section{References}

Bushman, J. A., and Robinson, J. S. (1968). British fournul of Anaesthesia, 40, 796.

Kirch, T. J., and De Kornfield, T. J. (1967). Anesthesiology, 28,

Macintosh, R. R., Mushin, W. W., and Epstein, H. G. (1963). Physics for the Anaesthetist, 3rd edn. p. 54. Oxford. Blackwell Scientific Publications.

Spalding, J. M. L. (1956). Lancet, 2, 1140

Sykes, M. K. (1969). Anaesthesia, 22, 668.

\title{
Environmental Conditions and Body Temperatures of Elderly Women Living Alone or in Local Authority Home
}

\author{
CARMENCITA B. SALVOSA， P. R. PAYNE， ERICA F. WHEELER
}

British Medical fournal, 1971, 4, 656-659

\section{Summary}

The environmental and body temperatures of two groups of elderly women have been measured. One group was living in a local authority home (L.A.H.) and the others in their own homes in North London. The L.A.H. provided a constant environmental temperature which was at all times higher than that of the private houses. In the latter group the ambient temperature was higher in bed-sitting rooms than in houses with separate living rooms and bedrooms.

Body temperatures in summer were similar throughout both groups. In winter the skin and mouth temperatures of the subjects living independently were lower than those in the L.A.H.

Four subjects who had low mouth temperatures measured during two consecutive winters did not prove to have lowered deep body temperatures. The diet of these four subjects was similar in respect of all nutrients to that found in other groups of subjects of the same age, and in relation to published dietary standards was adequate in all respects.

\section{Introduction}

Accidental hypothermia is now recognized as a real hazard among the elderly population (Duguid et al., 1961; Prescott et al., 1962; Trafford and Hopkins, 1963; Rosin and ExtonSmith, 1964; Royal College of Physicians of London, 1966; Barley and Evans, 1970). The elderly people affected often live alone and in poor circumstances and by reason of accident, illness, or mental confusion are unable to call for assistance. In a survey among patients admitted to hospitals in England and Scotland the Royal College of Physicians found that there was a clear relationship between environmental temperature and the incidence of accidental hypothermia.

Fox et al. (1971) reported experiments which throw doubt on the significance of low oral temperatures measured in cool conditions. The reliance on mouth temperatures to diagnose hypothermia may in time lead to the condition being regarded

\footnotetext{
Department of Human Nutrition, London School of Hygiene and Tropical Medicine, London WC1E 7HT

CARMENCITA B. SALVOSA, B.S., M.S., Research Worker

P. R. PAYNE, B.SC., Senior Lecturer

ERICA F. WHEELER, M.PHIL., Lecturer
}

as so trivial and frequent an occurrence that seriously ill patients with a lowered deep body temperature might be overlooked.

The aim of the present study was to investigate body temperatures and the occurrence of hypothermia in elderly women living alone compared with those living in a local authority home (L.A.H.). Mouth temperatures were measured morning and evening and a continuous monitoring method (Humphrey and Wolff, 1968) was used to measure skin temperatures at two sites. In addition, environmental temperatures in the subjects' homes were continuously recorded.

\section{Subjects and Methods}

Forty women aged 69 to 93 years took part in the study. One group of 20 subjects lived independently in their own homes in North London. The other group of 20 were residents in an L.A.H. in Hertfordshire.

\section{FIRST STUDY}

The studies were carried out between February and June 1970. Measurements were made in North London during the cold months of February and March, and were repeated in May and June, when the weather was warmer. Measurements in the L.A.H. were done in April.

The following data were collected for each subject:

Anthropometric.-Height, weight, and skinfold thickness (triceps, biceps, subscapular, and suprailiac).

Skin Temperatures.-The "Temperature Socially Acceptable Monitoring Instrument" (Humphrey and Wolff, 1968) is a portable monitoring instrument giving an integrated average temperature over a measured period of time. This was used to record skin temperatures for 24 hours. Each subject was fitted with two instruments in the morning, one being attached to the side of the neck, in a position which was not covered by hair or clothes, and the other on the sternum under the clothes. The recording cells were changed in the evening so that day and night values were obtained separately.

Mouth Temperatures.-Sublingual temperatures were taken in the morning and in the evening of the days on which the instruments were being worn. A low-reading clinical thermometer was used and was kept in the subject's mouth for three minutes, or longer if this was necessary in order to obtain constant reading.

Environmental Temparatures.-A thermohygrograph, which continuously records dry-bulb temperature and humidity, was taken into the subject's home. Recordings were made in the living room during the daytime and in the bedroom overnight. The thermohygrograph was placed in a position convenient to the subject, usually equidistant from the windows and the source of heat. 